\title{
3D MODELING OF TWO LOUTERIA FRAGMENTS BY IMAGE-BASED APPROACH
}

\author{
D. Ebolese ${ }^{\text {a }}$, M. Lo Brutto ${ }^{\text {a, } *}$, A. Burgio ${ }^{b}$ \\ ${ }^{a}$ Dept. of Civil, Environmental, Aerospace, Materials Engineering (DICAM), University of Palermo, Italy \\ (donatella.ebolese, mauro.lobrutto)@unipa.it \\ ${ }^{\mathrm{b}}$ Dept. of Cultures and Society, University of Palermo, Italy \\ aurelio.burgio@unipa.it
}

KEY WORDS: Photogrammetry, 3D Modelling, Archaeology, Pottery, Fragment.

\begin{abstract}
:
The paper presents a digital approach to the reconstruction and analysis of two small-sized fragments of louteria, a kind of large terracotta vase, found during an archaeological survey in the south of Sicily (Italy), in the area of Cignana near the Greek colony of Akragas (nowadays Agrigento). The fragments of louteria have been studied by an image-based approach in order to achieve high accurate and very detailed 3D models. The 3D models have been used to carry out interpretive and geometric analysis from an archaeological point of view. Using different digital tools, it was possible to highlight some fine details of the louteria decorations and to better understand the characteristics of the two fragments. The 3D models provide also the possibility to study and to document these archaeological finds in a digital environment.
\end{abstract}

\section{INTRODUCTION}

Over the last few years, many studies have focused on digital survey techniques (mainly short-range laser scanner and photogrammetry) to establish affordable and efficient pipelines for the production of artefact's digital 3D replicas (Koutsoudis et al., 2013), for geometric analysis (Barazzetti et al., 2010) and for visualization purpose (Gonizzi Bersanti et al., 2015).

Research efforts are increasingly focused on the measurement and 3D documentation of medium and small archaeological finds, such as to study the technological and morphological variability of artefacts (Bretzke \& Conard, 2012) and to create accurate models in a time- and resource-efficient manner (Olson et al., 2013).

The study of ancient pottery is a crucial phase in the archaeological interpretation, from different points of view, as for example the chronological or cultural aspects. The pottery is among the most important archaeological finds; it is generally found in fragments, which have to be documented, measured, drawn and classified. Nowadays, the introduction of 3D digital reconstruction techniques provides a considerable support to traditional hand-made and $2 \mathrm{D}$ pottery fragments recording and documentation.

The digital techniques offer new tools in order to study the pottery fragments and allow to define, for instance, some automatic documentation systems for archaeological classification and reconstruction of ceramics. By using the digital profile section of an archaeological oriented fragment and additional attributes belonging to the fragment, it can try to combine traditional classification methods with new techniques in order to get an objective classification scheme (Kampel et al., 2003). A large-scale pilot project using 3D laser scanning technology was carried out to identify the rotation axis and the profiles of about 1000 potsherds ceramics from several sites and periods (Karasik \& Smilansky, 2008).
A novel digital approach, based on the $2 \mathrm{D}$ recordings of single potsherds, was tested for the reconstruction of a complete vessel (Zvietcovich et al., 2016).

The 3D model, obtained by short-range laser scanner or photogrammetry, allows a better object comprehension and gives an important contribution to interpretative analysis. In addition to metric documentation, the $3 \mathrm{D}$ model allows to test reconstructions of the potteries with heterogeneous morphologies in their original state (Barreau et al, 2014) and different hypothesis of virtual restoration, to carry out a remote study of pottery (Arbace et al., 2013; Tsiafaki et al., 2016).

The paper describes the results of an interdisciplinary study for the 3D modeling and for the analysis of two louteria fragments found during the archaeological survey of the "Cignana Project". The main goals of the study are to evaluate an imagebased approach to produce 3D models of the two small-sized objects and to contribute to a better interpretation and understanding of these two fragments.

\section{THE ARCHAEOLOGICAL OVERVIEW}

\subsection{The "Cignana Project"}

Since 2007 the Department of Cultures and Societies of the University of Palermo, in cooperation with the Soprintendenza per $i$ Beni Culturali e Ambientali of Agrigento (Sicily, Italy), has been carrying out an intensive and systematic archaeological survey in the area of Cignana, a district located in south-central Sicily, between the Greek colonies of Akragas (nowadays Agrigento) and Gela (Figure 1). The project aims to acquire new archaeological data regarding the ancient settlement pattern, from Prehistory to Early Medieval Age (Burgio, 2012; Burgio, 2013). In the Cignana district, a roman villa with mosaics has been excavated by the Soprintendenza per $i$ Beni Culturali e Ambientali of Agrigento (Fiorentini, 1993-1994; Rizzo \& Zambito, 2010). Close to the villa there is

* Corresponding author 
one of the largest catacombs of western Sicily; there are also small villages, sacred areas, necropolis and rock-shelters of prehistoric ages, fortified villages and a sacred area of Archaic and Classical Ages, and a few sites of Roman Age (Orsi, 1928; Castellana, 1994; Castellana, 1995; Castellana, 1998; Lo Vetro, 2003). The most important resources of the area are connected with breeding activity, agriculture and minings of sulphur, the latter particularly in the Bronze and Roman Ages.

Currently, $20 \mathrm{~km}^{2}$ of the territory have been surveyed, and more than new 250 Topographic Units (UT) (archaeological sites, like farms and villages, scatters, tombs), from Prehistory to Late Antiquity/Byzantine period, have been identified. The area was also an important crossroad in the ancient road network, both in the Greek and Roman periods (Belvedere \& Burgio, 2009), because it is crossed by the road linking the Greek colonies of Siracusa and Selinunte, and it is very close to the roman via connecting Catania with Agrigento.

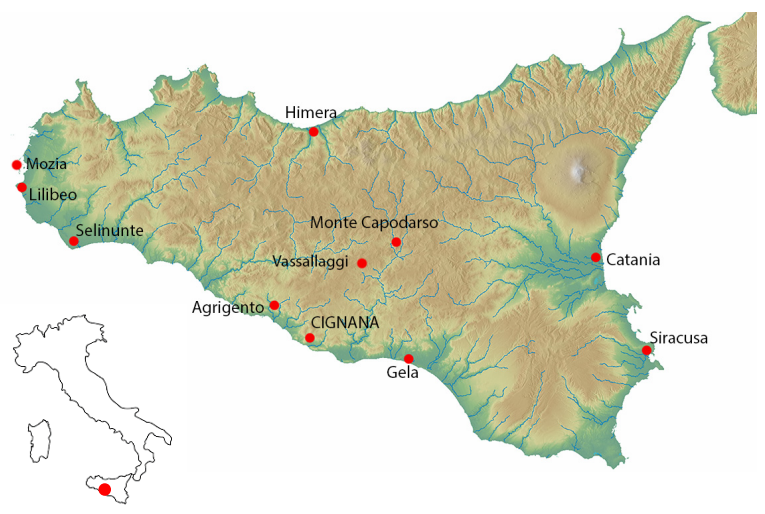

Figure 1. The area of Cignana.

\subsection{The Louteria fragments}

The louteria are large vases (the diameter is about $30 \div 40 \mathrm{~cm}$ ) with a broad rim, a wide and shallow body and a supporting column-base (up to 1 meter). The external face of the rim is often decorated with figurative bas-reliefs impressed with mould or roll (Figure 2). The function of these vases is linked to washing, and they are used both in sacred areas (like sanctuaries) and in private houses, in the rooms employed in sacred activities. The louteria are produced only in the Greek colonies of Sicily, as Gela, Agrigento, Selinunte and Himera. The characteristics of the louteria from Himera and Agrigento allowed to define four different typologies, which date from the middle of the $6^{\text {th }}$ to the $5^{\text {th }}$ century BC (Allegro, 1982).

The louteria fragments shown here were collected in two different sites identified by the survey. The sites are located on slight slope areas, and it can assume that one of them was a farm, and the second a rural sacred area. The pottery visible on the field (tiles and pithoi, black slip ware, coarse ware) allowed us to date both the sites during the late Archaic and Classical Ages (end of the $6^{\text {th }}$-beginnings of the $5^{\text {th }}$ century BC).

The two fragments are very small compared to the dimension of the whole vases. The first potsherd has an irregular shape and measures about $11 \mathrm{~cm} \times 8.8 \mathrm{~cm} \times 5 \mathrm{~cm}$; it is decorated with a Centauromachia bas-relief. The second one is also irregular and measures about $7.9 \mathrm{~cm} \times 7.5 \mathrm{~cm} \times 6.8 \mathrm{~cm}$; it is decorated with a Komòs scene.

The fragment with Centauromachia scene is a sloping rim, flat in the upper face, that can be related to the III type of Himera's typology and attributed to the end of the $6^{\text {th }}$ and $5^{\text {th }}$ century BC
(Allegro, 1982); this type is also documented in the hinterland of Gela (Bergemann, 2010).

The clay body, depurated and compact, is orange, pinkish in the core. A thick cream glaze is on the outer surface. The decoration is a sequence of three fighting groups, arranged from left to right (Figure 3). The status of conservation is not well, and only the group at the centre is fully visible; it is composed by a Centaur and a Lapith. The fighting groups are framed at the top by a band of ovuli (high $0.5 \mathrm{~cm}$ ), and at the bottom by astragali (high $0.5 \mathrm{~cm}$ ).

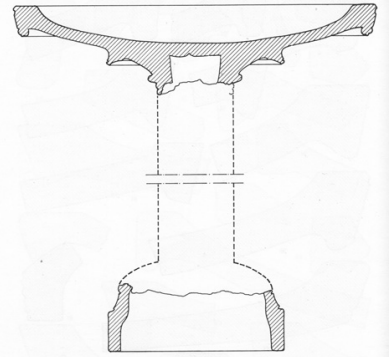

Figure 2. Louterion (from Allegro, 1982).

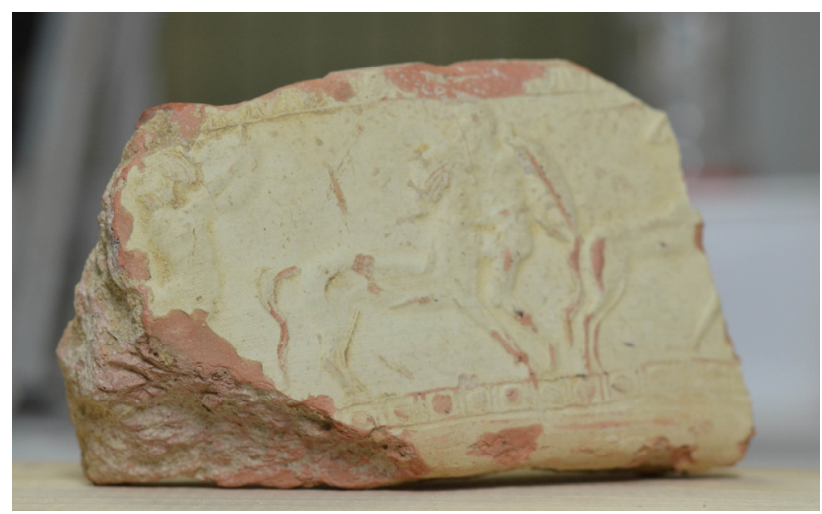

Figure 3. Potsherd decorated with Centauromachia scene.

On the left is visible only the Centaur, facing backwards and throwing a large object (maybe a stone) to the Lapith (missing). In the central group, the Centaur grips the Lapith, armed with helmet and shield. On the right, only the rump of the Centaur, maybe reared, and one of his arms gripping a tree are visible; a similar posture is on a louteria with Centauromachia from Agrigento (Marconi, 1929); it is likely that the Centaur is throwing the Lapith, which remains only a leg.

The details of this fragment, particularly the beard and hair of the Centaur in the left, the eye and the interior of the shield of the Lapith in the centre, and the muscle of the Centaurs suggest that the decoration were made by a new mould.

Similar pictures of Centauromachie are impressed on lips of louteria of the last quarter of the $5^{\text {th }}$ century $\mathrm{BC}$, from Agrigento (Marconi, 1929), where there are at least four different types. The fragment described here is similar to the second type of Agrigento, where a specimen with very similar decoration was found some years ago (De Miro, 2000). Others louteria decorated with Centauromachia scenes were found in some ancient towns and villages of Sicily, like Vassallaggi, Mozia and Selinunte (Allegro, 1982); the fragments from Mozia and Selinunte could have been produced in workshops of Agrigento.

The fragment with Komòs scene (Figure 4) is also a rim, concave on the upper face, maybe similar to the III type of the 
Himera's classification. The clay body is orange, depurated and compact; the glaze on the outer surface is very thick and light cream.

Three undressed satyrs dance around a column-krater, from which a pot, perhaps the neck of an amphora, seems to emerge. Also in this fragment, the status of conservation is not well, and only the central satyr is fully visible; he has the left arm up and the right down, the right leg up and the left down. The satyrs at the left and at the right are partially visible. The picture is framed at the top and at the bottom by two light engraved lines.

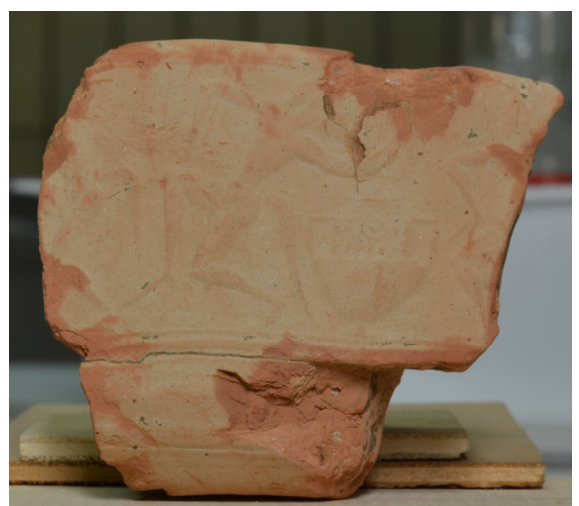

Figure 4. Potsherd decorated with Komòs scene.

Similar pictures are on louteria in the Archaeological Museum of Palermo, from Agrigento (Allegro, 1982; Marconi, 1929; Mangione, 2009). A similar decoration, even if with some differences regarding the comasti, is on the armrests of a terracotta throne found in Monte Capodarso (Sole, 2012), in the centre of Sicily. This demonstrates that the moulded decorations derived from sculpture, like these, were used in different kinds of artefacts.

\section{METHODOLOGY}

The 3D modelling of the two louteria fragments was carried out by the image-based approach, also indicates as image-based modeling (Remondino \& El-Hakim, 2006), using image measurements to recover 3D object information. At the present, this approach is mainly based on the integration of photogrammetry and computer vision.

For image acquisition, the set has been lighting up with a diffuse light and the fragments have been placed in front of a white background (Figure 5).

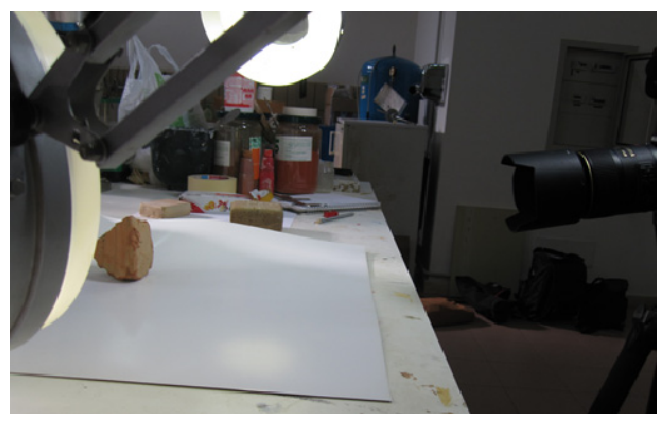

Figure 5. Image acquisition.

The camera has been kept fix. In order to acquire a complete dataset, a convergent images network has been planned around the two objects by rotating the objects on themselves, acquiring each image approximately every $20^{\circ}-30^{\circ}$.
Due to the very small size of the louteria fragments, a digital reflex Nikon D5100 camera, equipped with a $105 \mathrm{~mm}$ Nikon macro lens, was used. Macro lenses allow a high level of detail; at the same time, macro lenses present some limitations relate to calibration parameters, images sharpness, reduction of depth of field (Gallo et al., 2014). In particular, the reduced depth of field could cause problems in dense image matching, an increase in the noise level in the point cloud, topological errors and areas out of focus in textured 3D models (Nicolae et al., 2014).

The image acquisition of the fragment with the Centauromachia scene has been carried out with a camera-toobject distance of approximately $44 \mathrm{~cm}$ and a Ground Sample Distance (GSD) of about $0.020 \mathrm{~mm}$. A dataset of 105 images has been acquired.

The survey of the second fragment, with Komòs scene, has been carried out from a distance of $57 \mathrm{~cm}$, with a GSD value of 0.026 $\mathrm{mm}$. A dataset of 170 images has been acquired.

On the fragment with Komòs scene, a second test has been carried out with a Pentax Optio RZ18 compact digital camera, provided with a macro function. This test has been done to verify the possibility of using also low-cost consumer cameras for this particular photogrammetric purpose. Using the Pentax camera the images have been taken from a distance of about 20 $\mathrm{cm}$, obtained a GSD of $0.020 \mathrm{~mm}$. A dataset of 52 images has been acquired.

Photoscan Pro by Agisoft and ContextCapture by Bentley, two commercially available software packages that present a similar workflow, have been used to generate the $3 \mathrm{D}$ models. The image-based workflow carried out with the two software packages consisted of several steps: automatic camera calibration and image orientation, using the Structure from Motion (SfM) approach, bundle block adjustment and camera self-calibration, dense point cloud generation by dense image matching, polygonal model reconstruction and texture mapping. In order to scale the photogrammetric projects, some measures have been taken on fragments with digital callipers.

\subsection{Agisoft Photoscan data processing}

The Agisoft Photoscan Pro processing has been performed using the full image resolution for automatic image orientation by SfM approach, and $1 / 2$ of the full image resolution for dense point cloud generation. Mask constraints have been included for removing useless parts of the images and to focus image matching only on the objects.

During SfM, the reduced depth of field of the macro lens has caused a high noise level, so manual and automatic editing tools have been used to remove points with high re-projection error or with a high amount of noise. To obtain polygonal meshes, the dense point clouds have been triangulated establishing a maximum number of polygons equal to $1 / 5$ of the number of points generated in the dense point clouds.

For the fragment with the Centauromachia scene, about 73.000 tie points were extracted by SfM (Figure 6); the Root Mean Square (RMS) of image residual (i.e. re-projection error) was 0.87 pixels. The dense point cloud was about 16 millions of points. For the fragment with the Komòs scene, about of 48.000 tie points have been extracted by SfM (Figure 7); the RMS of image residual was 1.19 pixels. The dense point cloud was about 10 millions of points.

The dense point clouds were used to build the mesh 3D models of the two louteria fragments. High-resolution texture (8192 pixels x 8192 pixels) has also been generated for the final 3D model. 
The dataset of the fragment with the Komòs scene, acquired with the Pentax Optio RZ18 camera, has been processed with Photoscan Pro too. The same parameters of the Nikon D5100 datasets processing have been used. After the orientation step, about 33.000 tie points were extracted; the RMS of image residual (i.e. re-projection error) was 1.21 pixels. Compared to the Nikon datasets processing, the amount of noise was markedly increased. Moreover, a dense point cloud with fewer points (about 9 millions) was generated. The textured 3D model was generated with high-resolution texture too, but the quality of the texture was slightly less definite.

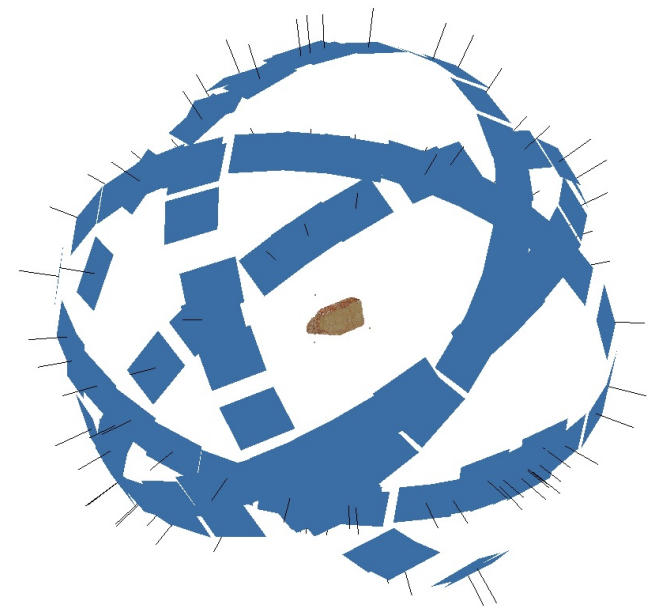

Figure 6. Photoscan image orientation of the fragment with Centauromachia scene.

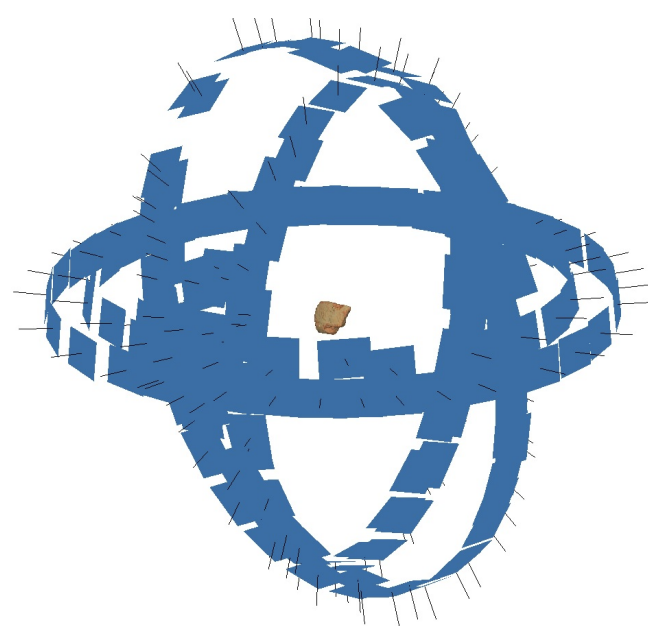

Figure 7. Photoscan image orientation of the fragment with Komòs scene.

\subsection{Bentley ContexCapture data processing}

ContextCapure presents two modules: ContextCapture Engine and ContextCapture Master. The Engine is the worker module that executes the processing steps. The Master module, indeed, is the graphical user interface to define input data and processing settings, to monitor the process and to visualize the results.

As mentioned earlier, ContextCapture workflow is similar to Photoscan one. Before to start image processing, it is possible to choose some estimation methods and advanced settings. For image orientation a "normal" keypoints density and a pair selection mode, that estimate tie points pairs mainly on image similarity, have been checked. As for Photoscan, masks constraints can be associated with the images but there are not editing tools to create them. So they have been imported from Photoscan.

ContextCapture showed more difficulty than Photoscan in the image orientation phase. In particular, in the case of blurry images or when the object surface is too homogenous, as in our terracotta fragments, some images were not properly oriented and were not used for the reconstruction process.

The dense point clouds for both fragments were obtained with a point sampling resolution of 3 pixels. For fragment with the Centauromachia scene, the orientation process extracted about 79.000 tie points (Figure 8); a RMS of 0.6 pixels was computed for image residuals. A dense point cloud of about 13 millions of points was generated. The orientation process of the fragment with the Komòs scene generated approximately 35.000 tie points; a RMS of about 0.7 pixels was also computed for image residuals (Figure 9). A dense cloud of about 7 millions of points was generated.

Due to the difficulty of the software to complete the image orientation step, the dataset acquired with the Pentax Optio RZ18 camera was not processed with ContextCapture.

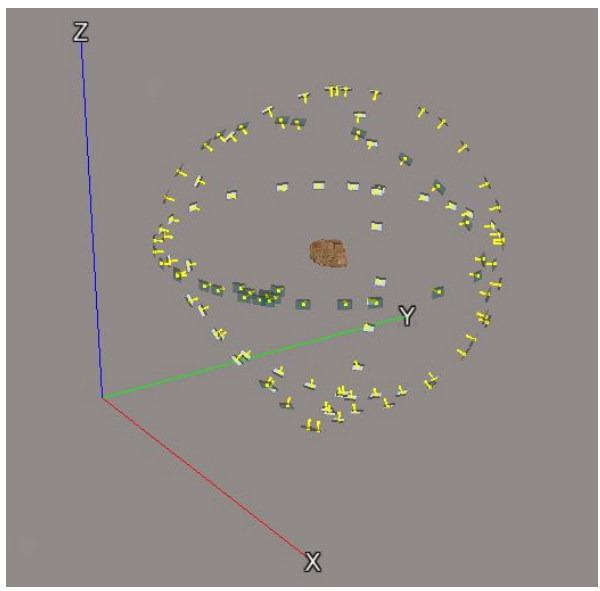

Figure 8. ContextCapture image orientation of the fragment with Centauromachia scene.

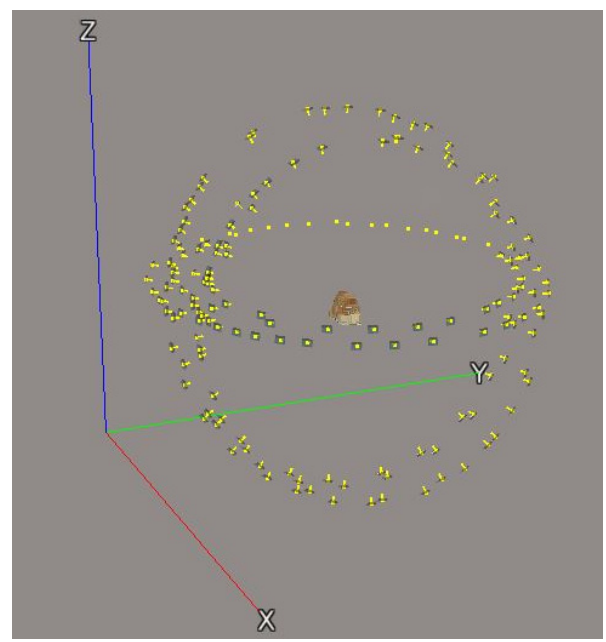

Figure 9. ContextCapture image orientation of the fragment with Komòs scene. 


\subsection{Image-based processing evaluation}

In order to assess the data produced by the image-based approach and to evaluate the two employed software, Photoscan Pro and ContextCapture, the dense point clouds of the two fragments were compared.

To compute the distances between the two dense point clouds, generated with Photoscan and ContextCapture, it has been applied the cloud-to-cloud distance function implemented in CloudCompare software package.

For the dense point clouds of the fragment with Centauromachia scene, it can be observed a good geometric congruence between the two dense point clouds, especially in the centre (blue color scale), where micrometric distance variations have been calculated. Instead on either side, it can be observed a greater difference (green color scale), in the order of millimetres (Figure10).

A worse result can be observed in the cloud-to-cloud distance evaluation of the two dense point clouds generated for the fragment with Komòs scene; an estimated distances even of about $1 \mathrm{~mm}$ in the centre of the dense point clouds (green color scale) was in fact computed (Figure 11).

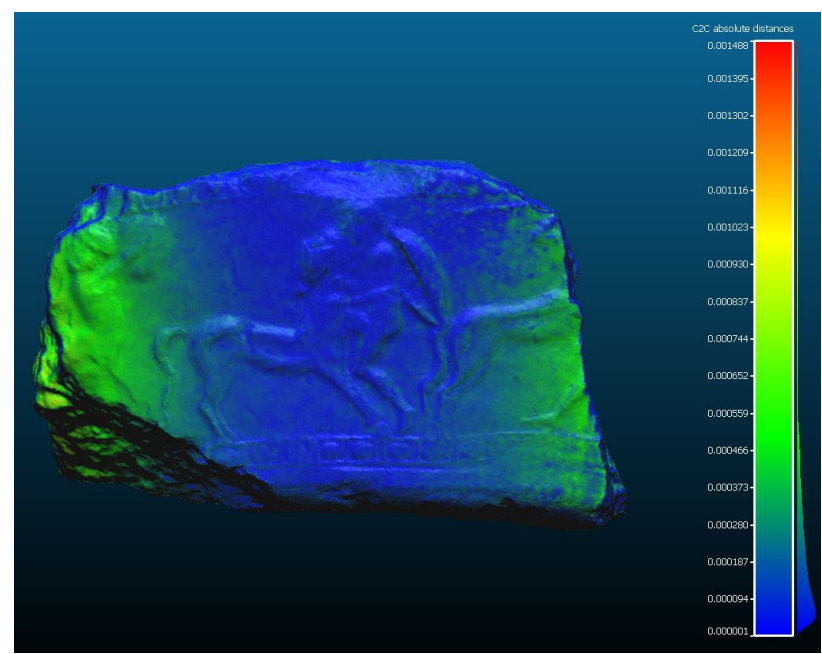

Figure 10. Cloud-to-cloud distance between dense point clouds of the fragment with Centauromachia scene.

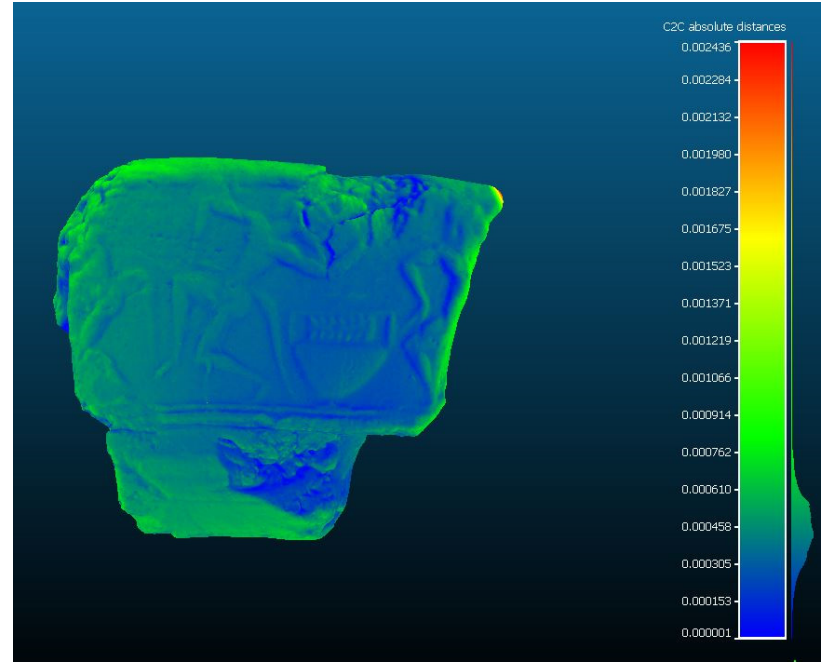

Figure 11. Cloud-to-cloud distance between dense point clouds of the fragment with Komòs scene.
The evaluation between the two dense point clouds of the fragment with Komòs scene, generated by Photoscan Pro from the Nikon D5100 dataset and from the Pentax Optio RZ18 dataset, shows good geometric correspondence (Figure 12). This last result will be studied in depth through further testing to evaluate the possibility of using low-cost consumer camera for surveys of very small objects.

From a quality point of view, the greater number of points generated for all the dense point clouds processed with Photoscan Pro, compared to ContextCapture ones, determined a better level of detail that allows the extraction of archaeological data for documentation and visualization purposes.

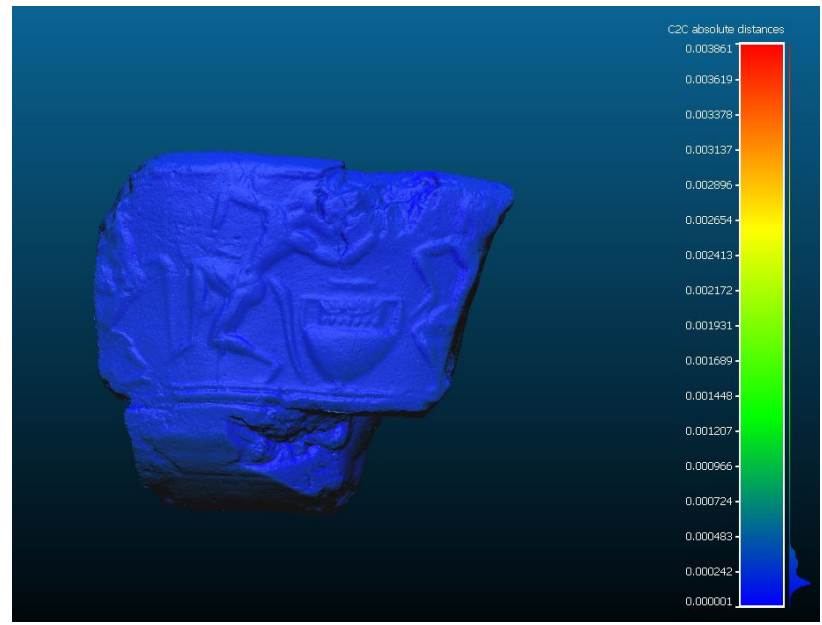

Figure 12. Cloud-to-cloud distance between dense point clouds of the fragment with Komòs scene.

\section{ARCHAEOLOGICAL ANALYSIS}

Documentation is a critical and delicate phase in archaeology for the classification of wares. The drawing of pottery fragments, based mainly on hand-made and two-dimensional methods or on digital CAD systems approach, is a standard process in archaeology. The possibility to obtain a digital 3D model of the fragments could be considered, afterwards, a very important step for archaeological analysis.

In archaeology, the production of a digital copy cannot be an endpoint; it is a starting point to analyse and to interpret the objects. Indeed, the possibility to observe details in the 3D models, the accurate 3D visualization for the remote study, virtual reassembly or exhibitions are important aspects that can contribute to the digital safeguarding too (Tsiafaki et al., 2016). The 3D models of the louteria fragments have been employed to test a methodology for digital representation of archaeological finds, to support the manual documentation and to decrease documentation time (Figures 13-14); moreover, the 3D models became a most effective support for archaeological studies.

In accordance with the traditional documentation, 3D models have been used to define and to depict, where possible, some features of the original louteria, first of all their diameters.

Considering the potsherds' size, the diameters cannot be determined with absolute certainty. Next to the traditional way to define them, the estimated diameters have been determined by defining the original orientation of fragments also in a 3D environment. Using a plan in a $3 \mathrm{D}$ environment it was possible to define the original orientation; some points have been identified on the model surfaces and exported in a CAD 
environment, where the estimated diameters have been fixed in a geometric way, as for the manual method (Figure 15).

Separately, the manual and digital procedures have been used to define the two diameters. For the fragment with the Centauromachia scene, we can estimate a diameter of about 33$35 \mathrm{~cm}$, with the traditional hand-made procedure, and of about 30-34 $\mathrm{cm}$ with the digital one (Figure 16). For the fragment with the Komòs scene, a diameter of about $30-33 \mathrm{~cm}$ with the hand-made procedure and of about $28-32 \mathrm{~cm}$ in a digital way (Figure 17).

Moreover single or multi-cross digital sections have been extracted from 3D models to compare them with hand-made sections (Figures 18 and 19).

Using some visualization tools and changing lighting direction in Meshlab, an open source software package for processing and editing point clouds and 3D triangular meshes, it is possible to observe details of bas-reliefs decorations hard to appreciate on the object or in the images. The visualization features of Meshlab can help graphically to highlight the peculiar characteristics of a 3D model.

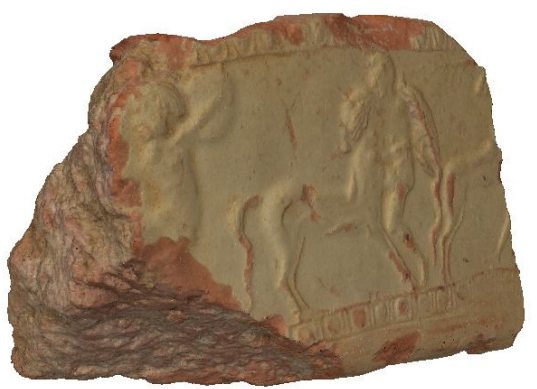

Figure 13. 3D model of the fragment with Centauromachia scene.

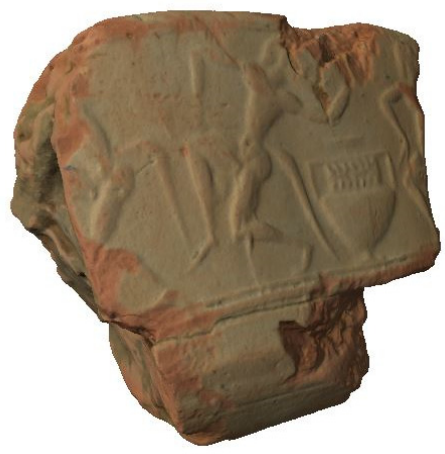

Figure 14. 3D model of the fragment with Komòs scene.

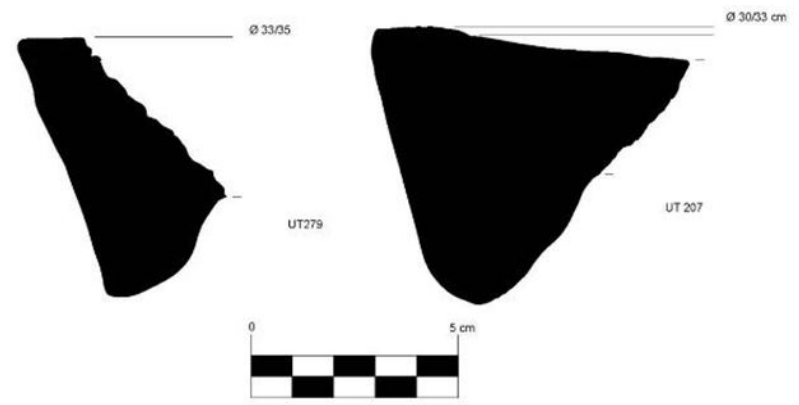

Figure 15. Manual orientation of the fragments with Centauromachia (on left) and Komòs (on right) scene.

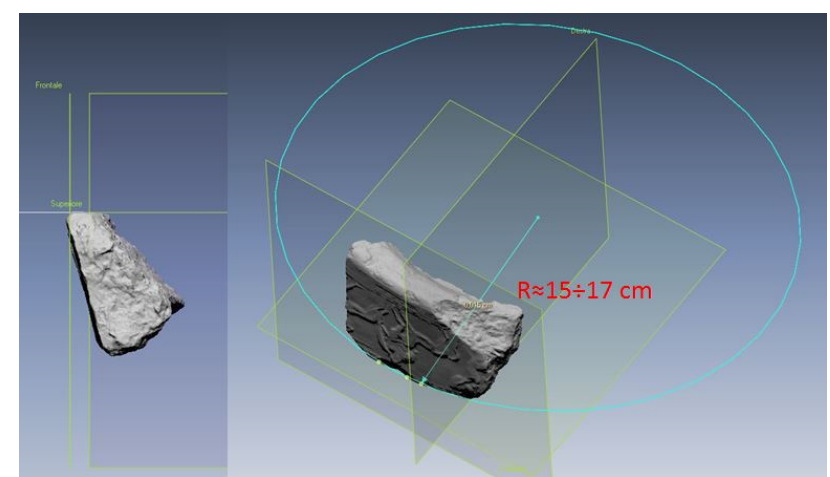

Figure 16. Orientation and estimated diameter of the fragment with Centauromachia scene.

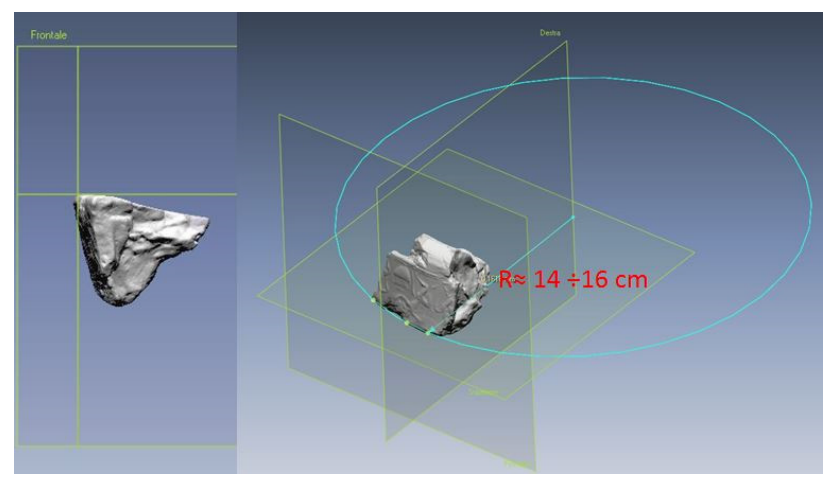

Figure 17. Orientation and estimated diameter of the fragment with Komòs scene.
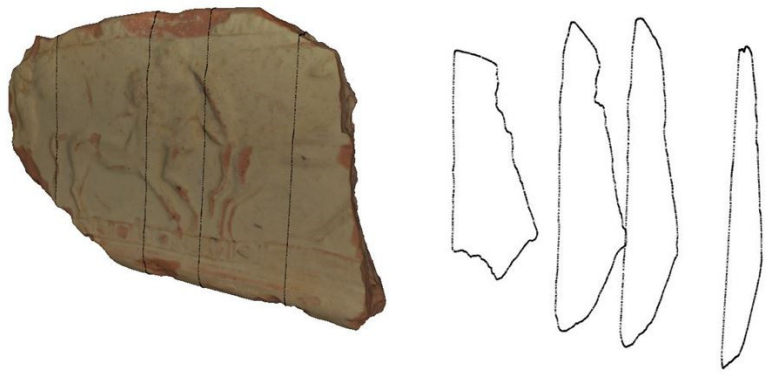

Figure 18. Digital cross sections of the Centauromachia fragment.
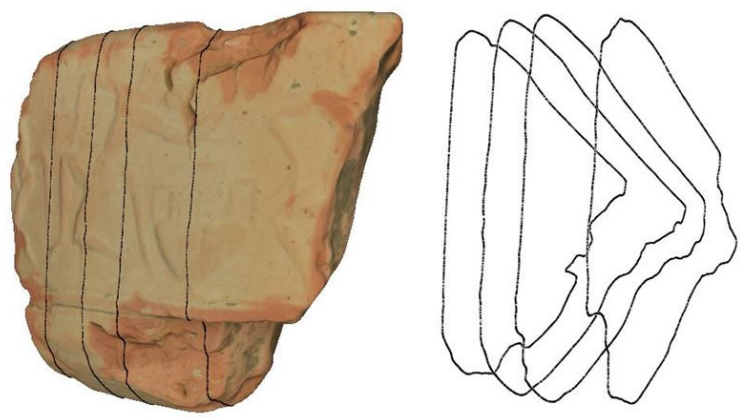

Figure 19. Digital cross sections of the Komòs fragment.

For the analysis of the two fragments, it has been used a Radiance Scaling filter for the depiction of surface shape through shading. The filter adjusts reflected light intensities in a 
way dependent on both surface curvature and material characteristics, enhancing surface concavities and convexities (Vergne et al., 2010).

In the fragment with Centauromachia scene, the efficiency of the Radiance Scaling filter enhances some surface details, like the stone in the hands of left Centaur, the interior of the shield in the central group, the tree and the rump of the Centaur in the right side (Figure 20).

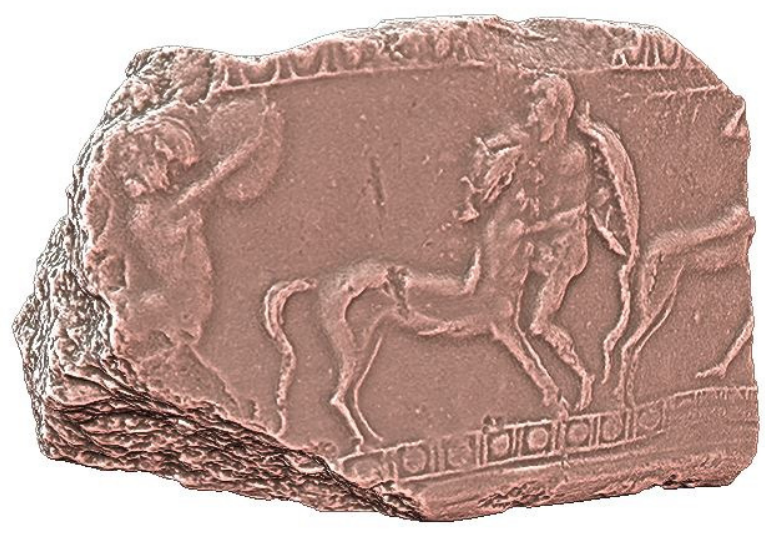

Figure 20. Digital visualization of the fragment with Centauromachia scene.

In the fragment with Komòs scene, some details became more evident too, like the muscles of the undressed satyrs, and the decoration of the neck of the column-krater. In particular, the digital filter allowed us to identify the pot which emerges from the krater: a cup (not an amphora, as previously assumed!), that is the vase usually used in the symposium in association with the krater (Figure 21).

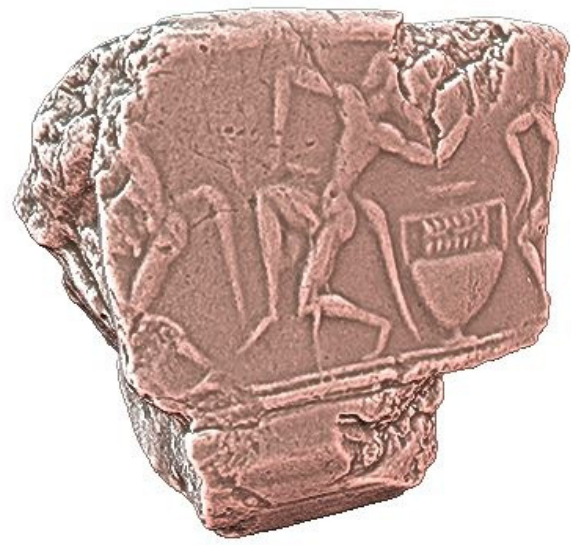

Figure 21. Digital visualization of the fragment with Komòs scene.

\section{CONCLUSIONS}

The paper shows that an accurate image-based survey of smallsize archaeological fragments can become an efficient tool to support the archaeological research and interpretation of ceramic finds.

Digital methodologies allow to decrease the number of very time consuming hand-made operations and to reduce fragments handling, by offering a better comprehension of them and gives an important contribution to interpretative analysis.
Archaeologists take advantage and can use digital reconstruction techniques to interpret and to present the pottery fragments (and, of course, other typologies of objects) in a complete way, to test the different hypothesis of virtual reconstruction and restoration or to carry out remote studies.

The level of detail of 3D models allowed to carry out metric observations and technical considerations directly on 3D copies, without the need to be in the same place or to handle original finds.

The possibility to control in a $3 \mathrm{D}$ environment these digital products contributes to defining an alternative methodology to describe and to record even smaller potsherds.

Both the tested software showed good results in the 3D reconstruction process of the datasets acquired with the digital reflex Nikon D5100 camera, equipped with a $105 \mathrm{~mm}$ Nikon macro lens. On the contrary, ContextCapture could not complete the image orientation step for the dataset acquired with the compact Pentax Optio RZ18 camera.

Dense point clouds and textured meshes allowed to carry out digital analysis of the two fragments to support the traditional one. Even though the fragments' size made it difficult to define with accuracy the diameters of the two original louteria, an automatic procedure to extract an estimated size of them was tested to define a reproducible digital methodology to achieve the same metric data with a truly significant reduction in time, compared to a classical and long-lasting drawing procedure.

Finally, one of the most important results of this process regards the details recognition, particularly in the fragment with Komòs scene. The use of digital filters and lights allowed to highlight some decoration characteristics on 3D models and gave an important contribution to the identification of figures and objects of the two bas-reliefs scenes. Digital filters became useful for visualization purpose too.

\section{REFERENCES}

Allegro N., 1982. Louteria a rilievo da Himera. In: Secondo Quaderno Imerese. L'Erma di Bretschneider, Roma, pp. 115166.

Arbace L., Sonnino E., Callieri M., Dellepiane M., Fabbri M., Iaccarino Idelson A., Scopigno R., 2013. Innovative uses of 3D digital technologies to assist the restoration of a fragmented terracotta statue. Journal of Cultural Heritage, 14(4), pp. 332345 .

Barazzetti L., Remondino F., Scaioni M., Lo Brutto M., Rizzi A., Brumana R.. 2010. Geometric and radiometric analysis of paintings. In: The International Archives of the Photogrammetry, Remote Sensing and Spatial Information Sciences, Vol. XXXVIII, Part. 5, pp. 62-67.

Barreau J. B., Nicolas T., Bruniaux G., Petit E., Petit Q., Bernard Y., Gaugne R., Gouranton V., 2014. Ceramics Fragments Digitization by Photogrammetry, Reconstructions and Applications. Proceeding of International Conference on Cultural Heritage, EuroMed, Lemessos, Cyprus, 3-8 November 2014.

Belvedere O., Burgio A., 2009. Sulla viabilità nel territorio di Palma di Montechiaro. Brevi note in margine al "Progetto

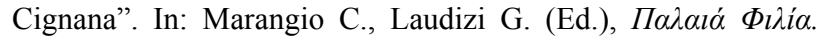
Studi di topografia antica in onore di Giovanni Uggeri, Galatina, pp. 515-530. 
Bergemann J., 2010. Der Gela-Survey. 3000 Jahre Siedlungsgeschichte in Sizilien, Biering \& Brinkmann, München.

Bretzke K., Conard N. J., 2012. Evaluating morphological variability in lithic assemblages using 3D models of stone artifacts. Journal of Archaeological Science, 39, pp. 3741-3749.

Burgio A. 2012. Il progetto "Cignana" (Naro-Palma di Montechiaro, Sicilia centro-meridionale). Prospezione archeologica intorno alla villa romana di Cignana. Primi dati sulle dinamiche del popolamento antico. In: Bergemann J., (Ed.), Griechen in Übersee und der historische Raum, Internationales Kolloquium Universität Göttingen (Göttingen, 13-16 Oktober 2010), Göttinger Studien zur Mediterranean Archäologie, 3, Rahden, pp. 127-139.

Burgio A., 2013, Dinamiche insediative nel comprensorio di Cignana. Continuità e discontinuità tra l'età imperiale e l'età bizantina. Sicilia Antiqua, X, pp. 31-53.

Castellana G., 1994. s.v. Palma di Montechiaro. In: Bibliografia Topografica della Colonizzazione Greca in Italia e nelle Isole Tirreniche, XIII, Edizioni della Normale, Pisa, pp. 300-310.

Castellana G., 1995. La necropoli protoeneolitica di Piano Vento nel territorio di Palma di Montechiaro. Regione Siciliana, Assessorato Beni Culturali e P.I., Palermo.

Castellana G., 1998. Il santuario castellucciano di Monte Grande e l'approvvigionamento dello zolfo nel Mediterraneo nell'età del Bronzo. Regione Siciliana, Assessorato Beni Culturali e P.I., Palermo.

De Miro E., 2000. Agrigento. I santuari urbani: l'area sacra tra il Tempio di Zeus e Porta V. L'Erma di Bretschneider, Roma.

Fiorentini G., 1993-1994. Attività di indagini archeologiche della Soprintendenza Beni Culturali e Ambientali di Agrigento. Kokalos, XXXIX-XL, II, 1, pp. 717-733.

Gallo A., Muzzupappa M., Bruno F., 2014. 3D reconstruction of small sized objects from a sequence of multi-focused images. Journal of Cultural Heritage, 15(2), pp. 173-182.

Gonizzi Barsanti S., Caruso G., Micoli L.L., Covarrubias Rodriguez M., Guidi G., 2015. 3D Visualization of Cultural Heritage artefacts with virtual reality devices. In: The International Archives of the Photogrammetry, Remote Sensing and Spatial Information Sciences, Volume XL-5/W7, 2015, pp. 165-172.

Kampel M., Sablatnig R., 2003. An automated pottery archival and reconstruction system. Journal of Visualization and Computer Animation, Vol. 14(3), pp. 111-120.

Karasik A., Smilansky U., 2008. 3D scanning technology as a standard archaeological tool for pottery analysis: practice and theory. Journal of Archaeological Science, 35, pp. 1148-1168.

Koutsoudis A., Vidmar B., Arnaoutoglou F., 2013. Performance evaluation of a multi-image $3 \mathrm{D}$ reconstruction software on a low-feature artefact. Journal of Archaeological Science, 40, pp. $4450-4456$

Lo Vetro D., 2003. L'Epigravettiano finale di Passo Falcone nell'agrigentino. Origini, XXV, pp. 47-74.
Mangione D., 2009. Scheda. In: Panvini R., Sole L., (Ed.), La Sicilia in età arcaica. Dalle apoikiai al 480 a. C. Catalogo della mostra, vol. II. Regione Siciliana, Assessorato Beni Culturali e I.S., Palermo, pp. 269-270.

Marconi P., 1929. Agrigento. Topografia ed arte. Vallecchi, Firenze.

Nicolae C., Nocerino E., Menna F., Remondino F., 2014. Photogrammetry applied to problematic artefacts. In: The International Archives of the Photogrammetry, Remote Sensing and Spatial Information Sciences, Riva del Garda, Italy, Vol. XL-5, pp. 451-456.

Olson B.R, Placchetti R.A., Quartermaine J., E Killebrew A., 2013. The Tel Akko Total Archaeology Project (Akko, Israel): Assessing the suitability of multiscale 3D field recording in archaeology. Journal of Field Archaeology, 38(3), pp. 244-262.

Orsi P., 1928. Miscellanea Sicula. I. Esplorazione topografica nell'Agro di Palma di Montechiaro (Girgenti). Bullettino di Paletnologia Italiana, XLVIII, pp. 45-62.

Remondino F., El-Hakim S., 2006. Image-based 3D Modelling: A Review. The Photogrammetric Record, 21, pp. 269-291.

Rizzo M. S., Zambito L., 2010. Ceramiche comuni ed anfore dal villaggio tardoantico di Cignana (Naro-Agrigento, Sicilia, Italia). In: Late Roman Coarse Wares 3, Archaeopress, Oxford, vol. I, pp. 293-300.

Sole L., 2012. Una statua fittile di divinità seduta da Capodarso: ipotesi di ricostruzione. In: Panvini R., Sole L. (Ed.), La Sicilia arcaica. Dalle apoikiai al 480 a.C., Proceeding of Convegno Internazionale, Caltanissetta, Italy, 27-29 March 2008, pp. 345358 .

Tsiafaki D., Koutsoudis A., Arnaoutoglou F., Michailidou N., 2016. Virtual Reassembly and Completation of a fragmentary Drinking Vessel. Virtual Archaeology Review, 7(15), pp. 67-76.

Vergne R., Pacanowski R., Barla P., Granier X., Schlick C., 2010. Radiance Scaling for Versatile Surface Enhancement. Proceeding of Symposium on Interactive $3 D$ graphics and games, Boston, United States, ACM, 2010.

Zvietcovich F., Navarro L., Saldana J., Castillo L. J., Castaneda B., 2016. A novel method for estimating the complete 3D shape for pottery with axial symmetry from single potsherds based on principal component analysis. Digital Applications in Archaeology and Cultural Heritage, 3, pp. 42-54. 